\title{
LINGUAGEM, REPRESENTAÇÃO E RECURSÃO NO DISCURSO METALINGUÍSTICO DE CLARICE LISPECTOR
}

\author{
Alana Kercia Barros Demétrio* \\ Maria Helenice Araújo Costa ${ }^{*}$ \\ Universidade Estadual do Ceará \\ Centro de Humanidades \\ Fortaleza, CE, Brasil
}

\begin{abstract}
Resumo: Este artigo problematiza noções sobre o atributo humano de construir sentidos. Objetiva discutir as noções de representação e recursão a partir da metalinguagem presente nos romances de Clarice Lispector. Adota, como referencial teórico, considerações tecidas por autores de diferentes áreas do conhecimento que, em seus estudos, fomentaram o debate epistemológico acerca destas noções, como o filósofo Kant, o linguista Izidoro Blikstein e o biólogo Humberto Maturana. À luz dessas contribuições teóricas, analisa trechos dos romances A cidade sitiada, Água viva e A paixão segundo G.H., em que identifica a presença de reflexões sobre o desafio intransponível da representação. Nos trechos analisados, observa a alusão a uma semiose não verbal oculta na dimensão de uma práxis anterior à língua, mas, ao mesmo tempo, dela tributária; e percebe a ideia de que os sujeitos constroem os sentidos no fluir das recursões da práxis do viver.
\end{abstract}

Palavras-chave: Linguagem. Representação. Recursão. Práxis do viver. Clarice Lispector.

\section{INTRODUÇÃO}

Os romances de Clarice Lispector são notadamente marcados pelo drama que constitui para os personagens o seu esforço de referir. Desde o romance de estreia, Perto do coração selvagem, a narrativa da escritora entrelaça a trajetória de seus protagonistas ao confronto com a linguagem. Mesmo quando não ocupa o primeiro plano, como ocorre na obra mencionada, esse confronto aparece no discurso construído por Clarice: "Palavras muito puras, gotas de cristal. Sinto a forma brilhante e úmida debatendo-se dentro de mim. Mas onde está o que quero dizer, onde está o que devo dizer? Inspirai-me, eu tenho quase tudo; eu tenho o contorno à espera da essência; é isso?" (LISPECTOR, 1998f, p. 69).

Conforme aponta Nunes (1995), a estratégia empregada por Clarice, de fazer voltarse a linguagem sobre si mesma, intensifica-se quando o estilo da escritora assume um nível mais abstrato e alegórico, que já se delineia em $A$ cidade sitiada e sofre um adensamento em $A$ maçã no escuro. De fato, a inquietação do protagonista de A maçã no escuro com a linguagem é tão contundente que nele desencadeia a determinação de

\footnotetext{
* Doutoranda do Programa de Pós-Graduação em Linguística Aplicada (UECE). Bolsista da Coordenação de Aperfeiçoamento de Pessoal de Nível Superior (CAPES). E-mail: alanakerciab@ gmail.com.

** Doutora em Linguística (UFC). Professora do Curso de Letras e do Programa de Pós-Graduação em Linguística Aplicada (UECE). E-mail: mariahelenicearaujo@gmail.com.
} 
reconstruí-la: "Sua reconstrução tinha de começar pelas próprias palavras, pois palavras eram a voz de um homem" (LISPECTOR, 1998c, p. 131). Uma vez que a busca por essa reconstrução torna-se a temática central dessa obra, o discurso metalinguístico permeia toda a narrativa.

E não é apenas no interior dos conflitos dos personagens que Clarice constrói as reflexões sobre o dizer. Em A hora da estrela, a metalinguagem aparece também na Dedicatória do autor, espécie de prólogo com que o narrador criado pela escritora introduz a história de Macabéa: "Mas que ao escrever - que o nome real seja dado às coisas. Cada coisa é uma palavra. E quando não se a tem, inventa-se-a. Esse vosso Deus que nos mandou inventar. Por que escrevo? Antes de tudo porque captei o espírito da língua e assim às vezes a forma é que faz conteúdo" (LISPECTOR, 1998b, p. 18).

Observando os diversos exemplos de manifestação do discurso metalinguístico nos romances da autora, percebemos que as reflexões que ela constrói em torno da linguagem abordam o tema de maneira ampla, extrapolando cogitações sobre o ato da escrita ou sobre o fazer literário, as quais encontramos com frequência no trabalho de outros escritores. Em relação a estas, as reflexões claricianas se destacam por abranger conteúdos ancorados nas raízes filosóficas dos estudos da linguagem. São questões pertinentes ao pensamento, à cognição, à problematização do mundo extramental e da noção de verdade ${ }^{1}$ e à noção de representação.

A noção tradicional de representação, que fundamenta a crença na linguagem como instrumento de acesso ao real, impulsionou, por exemplo, o projeto do protagonista de $A$ maçã no escuro. Nesse romance, o personagem Martim propõe, de maneira semelhante à dos filósofos analíticos, abolir a linguagem convencional em nome de um modo de exprimir a realidade sem deformações. Embora fracassando nesta que era sua intenção original, ele se vê vitorioso ao compreender, finalmente, como recurso frutífero a plasticidade da linguagem.

Conforme visto em Barros e Costa (2015), o desenrolar do conflito de Martim não é, contudo, linear. Não obstante a ansiedade do personagem por readmitir, ao final do romance, a linguagem comum, suas descobertas sucedem não exatamente por apaziguar a angústia, a sua e provavelmente também a do leitor, em face de um mundo indizível e de uma alma inefável, mas por denunciar um tipo de relação entre linguagem e realidade muito mais complexa do que a de correspondência especular.

Assim como vimos que não há desfecho possível para o conflito entre tal angústia e tal consciência de complexidade em $A$ maçã no escuro, entendemos que também não existe conclusão definitiva para a problematização metalinguística desenvolvida nos demais romances claricianos, seja por meio das reflexões de um narrador, seja através da voz e atitude dos personagens. Com o objetivo de discutir as noções de representação e recursão a partir do discurso metalinguístico presente nesses romances, analisamos trechos das seguintes obras: A cidade sitiada, Água viva e A Paixão segundo G.H., que a nosso ver são fortemente alusivas a essas noções.

\footnotetext{
${ }^{1} \mathrm{O}$ termo verdade é tomado aqui na acepção contestada por Maturana (2001, p. 149), em alusão ao suposto fundamento utilizado para "[...] conotar uma realidade independente do que fazemos como observadores, seja como uma referência pela qual validamos nossas afirmações, ou como um argumento que lhes dá universalidade".
} 
Na seção 2 deste artigo, apresentamos uma breve discussão teórica a respeito da espécie de trajetória que se delineia entre a desestabilização do princípio de representação na linguagem e a construção da noção de recursão, que consideramos uma coerente alternativa antirrepresentacionista. $\mathrm{Na}$ seção 3, analisamos trechos de romances claricianos debatendo, a partir das elucubrações metalinguísticas presentes no discurso que compõem, o percurso conceitual de que tratamos. Por fim, tecemos no último segmento alguns comentários acerca dos resultados mais relevantes e da pertinência da discussão empreendida.

\section{DA REPRESENTAÇÃO À RECURSÃO}

A resistência que as palavras oferecem aos usos que delas fazemos, os malentendidos inscritos em nossas interações cotidianas, nossas dificuldades de compreensão, esses aspectos, confrontados à crença, ainda predominante no senso comum, de que à linguagem caberia designar os supostos significados essenciais de um mundo naturalmente discretizado, corroboram a ideia de uma falha de performance dos falantes ou de uma imperfeição das línguas naturais.

Chamando a atenção para as inquietações desencadeadas por essa suposta falibilidade do aparato linguístico humano, Magro (1999) nos lembra dos esforços empreendidos ao longo do tempo para minimizar, ou mesmo eliminar, o pretenso problema. Entre esses esforços, a autora aponta a proposta do Calculus universalis, de Leibniz, que consiste no "[...] projeto de uma linguagem artificial, desprovida de qualquer ambiguidade" (MAGRO, 1999, p. 96), e o intento de Frege de inaugurar por meio do simbolismo lógico uma linguagem perfeita, o Begriffsschrift, “[...] uma conceitografia, que se define como uma linguagem formular de pensamento puro, imitada da linguagem aritmética, um meio de evitar mal-entendidos e erros no pensamento originados principalmente da linguagem ordinária" (MAGRO, 1999, p. 96).

Também poderíamos incluir em tais esforços de dissolver as imperfeições da língua cotidiana a teoria proposta no Tractatus por Wittgenstein, que, em seus primeiros estudos, atribuiu ao mau uso da linguagem a emergência dos problemas filosóficos. Wittgenstein procurou resolver o problema de traduzir a realidade por meio de notações que funcionassem como diagramas capazes de espelhar a estrutura lógica do mundo, postulando que "[...] a proposição é figuração da realidade, pois [se conhece] a situação representada por ela quando [se entende] a proposição" (WITTGENSTEIN, 1968, p. 72, $\S 4.021)$.

A crença na possibilidade de se estabelecer uma relação biunívoca entre linguagem e realidade, na qual estão apoiadas as propostas do cálculo, da conceitografia e da figuração, pressupõe que a realidade discretizada já existe e que à linguagem caberia apenas o papel mal desempenhado de exprimi-la.

Essa crença, fundamento das propostas dos filósofos analíticos, está situada na trajetória do empreendimento humano de construir conhecimento sobre a origem da existência, a constituição dos fenômenos naturais e o funcionamento das práticas socioculturais, elementos que tinham por muito tempo sido atribuídos a entidades 
mitológicas. Conforme explica Costa (2007), na história da filosofia, as especulações cosmológicas e ontológicas levam à problematização do próprio conhecimento (virada epistemológica); da comunicação desse conhecimento (virada linguística), e, em seguida, da relação de mútua constitutividade entre uma e outra instância (virada pragmática), quando o reducionismo lógico cede lugar à noção de que "[...] a realidade é algo dinâmico que emerge com nossas práticas sociais, entre as quais estão os diversos usos da linguagem" (COSTA, 2017, p. 23).

A pretensão dos filósofos analíticos é, assim, precedida pelo problema da validação da representação. Segundo Ghiraldelli (2008), a pergunta sobre o mundo feita pela filosofia antiga de modo direto (intentio recta) passa a ser formulada pela filosofia moderna de modo indireto (intentio obliqua). Como explica o autor, a indagação sobre o que há de real no mundo passa a implicar dúvida sobre qual representação do mundo seria válida, verdadeira; a questionar mesmo se haveria conhecimento do mundo. Fundamental no desenvolvimento dessa reformulação epistemológica foi a tentativa de Kant ([1781] 2009) de demonstrar, com a Crítica da razão pura, que a racionalidade não é absoluta.

Assim como, nas ciências naturais, Copérnico afastou a hipótese geocêntrica em favor da ideia de que os corpos celestes giravam em torno do Sol, Kant promoveu, no seio da filosofia, uma mudança de perspectiva que abalou a postura dogmática dos pensadores clássicos. Com a revolução copernicana filosófica, Kant sustenta que "[...] a verdade concerne, não à essência última das coisas, mas ao modo como as conhecemos" (FIGUEIREDO, 2005, p. 25), propondo a substituição da ontologia, com sua pretensão de obter o conhecimento das coisas em si, pelo "[...] título modesto de uma simples analítica do entendimento puro" (KANT, 2009, p. 179).

A justificativa reside naquilo que Kant (2009) denomina o problema geral da razão pura, isto é, a insuficiência da faculdade pura da razão diante da tentativa de dar respostas às indagações metafísicas. Para o filósofo, o uso dogmático, acrítico, da razão produz postulados infundados, parciais, contestáveis; é necessário, em face disso, avaliar os limites e potencialidades da razão em relação aos objetos apresentados pela experiência.

Se, por um lado, "[...] as categorias não se fundamentam, quanto a sua origem, na sensibilidade" (KANT, 2009, p. 180), são por outro lado juízos apriorísticos sem validade objetiva (abstratos), que só adquirem sentido, significação, ao tornarem-se sensíveis, ao receberem seu objeto "[...] pela intuição empírica ${ }^{2}$, da qual [eles são] simples forma" (KANT, 2009, p. 174). A afecção da sensibilidade, por sua vez, não constitui, como explica Kant, a representação do conhecimento de um objeto, pois "[...] pela simples intuição nada é pensado" (KANT, 2009, p. 184); os objetos nos são apresentados pelos sentidos não como são, mas como nos aparecem.

Conforme o filósofo, por ser a intuição sensível possibilidade única para nós (não somos dotados de outro tipo de intuição), os sentidos permanecerão para sempre desconhecidos como objetos do entendimento puro, isto é, apenas num plano transcendental (que ignoramos existir), poderíamos afirmar que o entendimento ${ }^{3}$ nos

\footnotetext{
${ }^{2}$ Segundo Kant (2009), “[...] sensação é o efeito que um objeto causa na capacidade de representação, quando o mesmo objeto nos afeta. A intuição é chamada de empírica quando, mediante sensação, referese ao objeto" (KANT, 2009, p. 31, grifos do autor).

${ }^{3}$ Kant (2009) afirma que a intuição permitida por nossa natureza abrange "[...] apenas a maneira como nos afetam os objetos. Já o entendimento é a faculdade de pensar o objeto da intuição sensível. Nenhuma dessas propriedades é preferível à outra. Sem sensibilidade, nenhum objeto nos seria dado e, sem entendimento,
} 
apresenta as coisas tais quais elas são, mas, sem relacionar categorias e objetos, sem submeter a razão ao plano empírico, a "[...] realidade objetiva não pode, de forma alguma, ser conhecida" (KANT, 2009, p. 185). Apenas como unidade "[...] o entendimento e a sensibilidade podem determinar os objetos em nós" (KANT, 2009, p. 187), razão pela qual os objetos simplesmente inteligíveis a nada se referem e "[...] as coisas são conhecidas por nós somente como parecem ser" (KANT, 2009, p. 182, grifos nossos).

A tese kantiana acerca de nossa incapacidade de conhecer as coisas de fato, objetivamente, é interpretada por Rego (2006) como uma crítica que se estende ao discurso. Conforme o autor,

\begin{abstract}
Kant afirma que não há um critério interno à linguagem (evidentemente tampouco externo) capaz de garantir a correspondência da linguagem em relação às coisas em si mesmas [...]. Em termos formais, isso significa: não podemos determinar o valor de verdade dos nossos enunciados (REGO, 2006, p. 162).
\end{abstract}

De nossa parte, não enxergamos na renúncia de Kant a um conhecimento das coisas em si mesmas, seja mediante um racionalismo dogmático, seja a partir de um empirismo autônomo, a indicação de um problema a residir na linguagem. $\mathrm{O}$ movimento de desconstrução que com sua crítica Kant promove no universo convicto da filosofia transcendental não nos parece alcançar a dimensão linguística. Nosso posicionamento encontra apoio nas considerações de Derrida a respeito do problema da linguagem em face da questão do caráter crítico em filosofia. Ainda que para discordar de Derrida, é Trevisan (2012) quem nos apresenta essas considerações:

\footnotetext{
Derrida acusa a filosofia transcendental de uma "ingenuidade natural" quanto ao problema dos limites e da origem mesma da linguagem e, com ela, do próprio discurso filosófico empregado e de sua legitimidade - para o filósofo transcendental, a linguagem seria um fato, talvez até um "fato da razão", a ser assumido acriticamente e que "exclui a reflexividade" (TREVISAN, 2012, p. 82).
}

A nosso ver, essa ingenuidade não é superada; ao problematizar a representação, nosso conhecimento absoluto do real, Kant parece ignorar o papel desempenhado pela linguagem na questão, reportando-se sempre ao pensamento, aos juízos formulados pelo entendimento para moldar o conteúdo das experiências, como se não houvesse opacidade no dizer e os sentidos fossem apriorísticos, dele independentes.

A ausência desse exame crítico no discurso do filósofo nos impele a reconhecer em seus postulados o pressuposto da linguagem como simples instrumento, neutro e eficiente, de que se utilizariam os indivíduos para organizar racionalmente os dados captados pelos sentidos. Concordamos assim com Derrida, para quem "[...] essa ausência representaria uma 'zona cinzenta' em que linguagem e pensamento originário se confundem e se isentam de qualquer reflexão acerca de sua legitimidade” (TREVISAN, 2012, p. 83).

nenhum seria pensado. São vazios pensamentos sem conteúdo; são cegas intuições sem conceitos" (KANT, 2009, p. 53-54). 
Longe de ser um problema bem resolvido, a relação linguagem-pensamento esteve sempre a se imiscuir na preocupação humana com o conhecimento da realidade. Segundo Blikstein (2003), a hipótese da modelagem linguística do universo não livrou a significação da necessidade de recorrer a uma dimensão anterior à experiência verbal, a "[...] percepção-cognição, onde justamente se fabricariam os referentes/objetos mentais/unidades culturais" (p. 39).

A famigerada hipótese sapir-whorfiana é referida por Blikstein como basilar na tendência de considerar a língua como organizadora da estrutura conceitual do mundo. A hipótese, conforme a qual "[...] categorias mentais como o tempo, o espaço, o sujeito e o objeto são explicadas pelas estruturas linguísticas" (BLIKSTEIN, 2003, p. 41), influenciou o trabalho de muitos linguistas, fomentando a ideia de que a palavra antecede o pensamento, e os significados das coisas não existem fora da linguagem.

Conforme Blikstein, a assunção irrefletida dessa hipótese deixa obscuro um imprescindível aspecto do mecanismo de significação, a experiência perceptiva. $\mathrm{O}$ autor argumenta que nosso sistema perceptual estaria aparelhado de uma práxis (prática social) que o habilitaria a transformar a realidade em referente. Noutras palavras, nossa percepção da realidade seria atravessada por mecanismos cognitivamente desenvolvidos a partir das condições sócio-históricas do momento e lugar que compartilhamos.

A tese bliksteiniana é a de que a práxis opera na percepção-cognição “[...] gerando conteúdos visuais, tácteis, olfativos, gustativos, na dimensão cinésica e proxêmica [...], independentemente da ação e do recorte da linguagem linear" (BLIKSTEIN, 2003, p. 66); haveria assim uma semiose não verbal eclipsada pela primazia atribuída à linguagem. Por outro lado, Blikstein admite que, diante de nossa crescente imersão nos processos de socialização, “[...] nossa percepção/cognição vai-se amoldando, em geral, à lógica linear discursiva e é muito difícil pensar o mundo de outra maneira" (BLIKSTEIN, 2003, p. 68).

Como explica o autor, não havendo outra forma de capturar essa semiose enredada na dimensão da práxis, recorremos à língua para materializá-la. Esta, por sua vez, interage com a práxis e a reitera, afetando nossa experiência perceptivo-cognoscente e modelando, portanto, o referente, isto é, fabricando a realidade.

O dinamismo do esquema proposto por Blikstein reforça a desconstrução da ideia do real apriorístico, discretizado, e oferece coerência à explicação da relação entre linguagem, cognição e realidade apresentada pelo autor. Em contrapartida, observamos que essa explicação preserva em certa medida a noção da existência de uma espécie de dimensão anímica (ainda que socialmente motivada), dotada de propriedades peculiares para captar a instrução do meio e, portanto, fabricar representações.

Sem conseguir livrar-se da recorrência ao conceito de representação, a proposta bliksteiniana enquadra a experiência perceptiva como um modo de organizar o miolo difuso presente no domínio das interações produzindo imagens redutíveis ao organismo, isto é, a nosso domínio fisiológico, garantindo nele um lugar para a mente. Alertando-nos contra a armadilha epistemológica que a nosso ver apanha Blikstein, Magro (2000), apoiada nos estudos do biólogo Maturana, em sua biologia do conhecer, assevera que

Para explicar cognição e linguagem, não precisamos trazer para dentro de nós, sob a forma de representações de quaisquer naturezas, o que vivemos em nossas interações, nem os mundos que nelas constituímos, embora esses dependam claramente de nossa corporalidade, a cada instante [...] (MAGRO, 2000, p. 272). 
De acordo com Magro (1999b), em vez de constituir uma entidade psíquica transcendente, a mente é o próprio espaço relacional, interativo, no qual desempenhamos nossas atividades, recorrentes e recursivas. Assim, conforme esclarece a mesma autora (1998), perceber não é captar os traços de uma realidade externa para constituir representações internas a serem posteriormente computadas; nem sequer existe uma dimensão interna, um sistema cognitivo aparelhado de conceitos apriorísticos a ditar de que modo deve ser o mundo percebido.

\begin{abstract}
Como um ato cognitivo, perceber nos envolve em nossa corporalidade e em nossa história de seres linguajantes num meio, entrelaçando linguagem e emoção no conversar, como um modo de vida especificamente humano. É nesse conversar que criamos os objetos, distinguindo-os e nomeando-os, e passando posteriormente a tratá-los como independentes dos atos pelos quais os trouxemos à existência (MAGRO, 1998, p. 180, grifo da autora).
\end{abstract}

Compreendemos, pois, que a experiência perceptiva e a linguagem - o linguajar, nos termos de Maturana -, não se desenvolvem em dimensões desmembráveis, como verificamos ocorrer no esquema explicativo de Blikstein. Como observadores linguajantes, perceber e explicar coordenadamente é o nosso modo de estar no mundo.

Consoante Maturana (2001), na história da convivência promovemos coordenações consensuais ${ }^{4}$ de comportamentos. Essas coordenações são resultado da convivência de nossas transformações, de mudanças estruturais desencadeadas em nós pela interação com outros sistemas determinados estruturalmente ${ }^{5}$, “[...] de modo que uma história de interações recorrentes é uma história de desencadeamentos estruturais, de mudanças estruturais mútuas entre o meio e o ser vivo, e o ser vivo e o meio" (MATURANA, 2001, p. 76).

Segundo o autor, uma história de interações dura enquanto houver conservação de organização dos participantes. Assim, enquanto há conservação de nossa organização, mantemo-nos vivos. Por outro lado, há rearranjo de nossa configuração estrutural a partir das perturbações que admitimos em nossa ontogenia. Conforme explana o biólogo, da contingência dessas mudanças estruturais, no fluir de nosso viver em acoplamento com o meio, surgem coordenações consensuais de condutas. Como organismos, engajamo-nos num mútuo ajustamento por meio do qual nos constituímos e preservamos; simultaneamente, como observadores linguajantes, percebemos e explicamos nossas experiências, operando em coordenações consensuais de ações de modo a validar contingencialmente as explicações.

Ainda de acordo com Maturana, quando há uma história de interações recorrentes, produzimos uma dinâmica de recursões de consenso, isto é, "[...] uma operação num domínio de coordenações consensuais de coordenações consensuais de ações" (MATURANA, 2001, p. 131). A linguagem, nesse sentido, ocorre quando “[...] duas ou

\footnotetext{
${ }^{4}$ Maturana (2001) faz distinção entre as noções de consenso e de acordo. Enquanto este último "[...] envolve a condição explícita da coincidência na ação sobre algo" (p. 71, grifo do autor), o consenso diz respeito a "[...] coordenações de condutas que se estabelecem como resultado de estar juntos em interações recorrentes" (p. 71).

${ }^{5}$ Conforme Maturana (2001), “[...] tanto ser vivo quanto meio são sistemas determinados estruturalmente” (p. 75).
} 
mais pessoas em interações recorrentes operam através de suas interações numa rede de coordenações cruzadas, recursivas, consensuais de coordenações consensuais de ações" (p. 130).

Concordamos com Magro (1999b) quando afirma que, nesse modo de conceber a linguagem, não há lugar para a ideia de representação. Como argumenta a autora, ao dispensar recurso à transcendência para descrever o modo como vivem os seres na linguagem, o pensamento de Maturana constitui uma viável alternativa ao representacionismo, pois rejeita tanto a noção de linguagem como ferramenta para a apreensão de um mundo externo, para a captação de "[...] objetos perceptivos independentes" (MAGRO, 1999b, p. 193), quanto o conceito de mente como entidade depositária de propriedades cognitivas apriorísticas ou de imagens armazenadas. $\mathrm{O}$ espaço mental corresponde nessa abordagem a "[...] um espaço de interações realizadas principalmente na linguagem, como modo de viver num recorrente e recursivo entrelaçamento de emocionar e conversar." (MAGRO, 1999b, p. 194).

Prescindir da representação não implica, na biologia do conhecer, negar o meio circundante e legitimar a autonomia solipsista da cognição, como sempre temeu a tradição filosófica clássica, porque, ao passo que é refutada a objetividade de um mundo cognoscível, há a premissa de que nós, como sistemas vivos, não operamos num vácuo, mas num meio que nos é comensurável em razão de nossa história de acoplamento estrutural. A regularidade do mundo não se dá com base em referências independentes de nós a assegurar a estabilidade absoluta daquilo que experimentamos, mas se estabelece a partir das coerências perceptivas resultantes de nossa história biossocial, de interações recorrentes nas quais coordenamos consensualmente os comportamentos que geramos.

"Quando dois ou mais organismos interagem recursivamente como sistemas estruturalmente plásticos, cada um deles vindo a ser um meio para a realização da autopoiese do outro, o resultado é um acoplamento estrutural ontogênico mútuo" (MATURANA, 1997, p. 146). O domínio de condutas encadeadas que compõem essa história recursiva decorrente do acoplamento ontogênico recíproco é referido por Maturana como domínio consensual.

Para o autor, o consenso não diz respeito à coincidência manifesta dos interactantes na ação coordenada; ele é efeito "[...] da convivência das transformações dos participantes na convivência” (MATURANA, 2001, p. 71), isto é, da coordenação em interações recorrentes das condutas geradas, a partir das mudanças estruturais desencadeadas pelas perturbações, no curso particular da ontogenia dos interactantes. Além dessa coordenação comportamental nas interações recorrentes, o domínio consensual abrange a "[...] coordenação comportamental recursiva sobre a coordenação comportamental" (MATURANA; VARELA, 1995, p. 71), o que faz da linguagem uma conduta que tem lugar nesse domínio.

Consoante Maturana (2001), o operar na linguagem é o fluir na recursão das coordenações de ação. A recursão é um fenômeno que remete à história de interações recorrentes, não como repetição de condutas sociais precedentes, mas como operação de coordenação de consensos prévios. Consistindo nesse fluir recursivo, a linguagem não é uma habilidade circunscrita ao sistema nervoso dos falantes, tampouco é um conjunto abstrato de relações entre símbolos. Como salienta o autor, nenhum comportamento, 
gesto, som ou postura particular constituem por si elementos linguísticos, muito menos são esses elementos dotados de conteúdo, com significados apensos; as palavras são modos de coordenar ações e coordenações consensuais de ações.

Nessa perspectiva, não resta espaço, pois, para qualquer relação de contiguidade entre mundo, linguagem e ser. Conforme reforça Maturana (1997), o conteúdo de um linguajar está no próprio fluir das coordenações consensuais de coordenações consensuais de ações. Os seres linguajantes, por sua vez, ao operar na linguagem, desencadeiam uns nos outros mudanças de estado que modulam suas respectivas dinâmicas estruturais.

\footnotetext{
Dito de outro modo, as palavras constituem operações no domínio de existência, como seres vivos, dos que participam na linguagem, de tal modo que o fluir de suas mudanças corporais, posturas e emoções tem a ver com o conteúdo de seu linguajar. Em suma, o que fazemos em nosso linguajar tem consequências em nossa dinâmica corporal, e o que acontece em nossa dinâmica corporal tem consequências em nosso linguajar (MATURANA, 1997, p. 168).
}

Esse enleio entre cognição, linguagem e ontogenia, esse vínculo mutuamente constitutivo que ata essas instâncias, é, nas palavras do biólogo, o suceder do viver na linguagem. Na conservação transgeracional desse modo de vida, que começou há três milhões de anos, "[...] nós explicamos nossas experiências com nossas experiências e com as coerências de nossas experiências" (MATURANA, 2001, p. 191), e é esse o fundamento da realidade; "[...] explicamos nosso viver com nosso viver" (MATURANA, 2001, p. 191).

\section{REPRESENTAÇÃO E RECURSÃO NA METALINGUAGEM DE CLARICE LISPECTOR}

Embora vinculados ainda a pressupostos de base essencialista, os primeiros passos teóricos em direção à desestabilização da ideia de representação como reprodução, cópia, reflexo, foram significativos para a compreensão da complexa e enigmática relação entre linguagem e realidade, ensejando como caminho possível a construção da noção de recursão. Em nosso modesto recorte da vasta trajetória delineada entre esses passos inaugurais e o ponto de chegada que destacamos, a qual se materializa em mais de um campo de conhecimento, relevamos alguns posicionamentos para guiar nossa discussão. Neste espaço analisamos 7 exemplos (1 trecho de A cidade sitiada, 2 trechos de Água viva e 4 trechos de A Paixão segundo G.H.) que a nosso ver aludem a esses posicionamentos, os quais se configuram como pontos distintos nesse intervalo entre os polos da representação e da recursão.

A ausência de linearidade e de epílogo que, como mencionamos na introdução, marca o desenvolvimento do discurso em questão nos desobriga a usar o aspecto cronológico como critério de organização desses trechos na condução de nossa análise, tanto no que diz respeito à sequência de publicação dos romances quanto no que se refere à posição do excerto na narrativa. Os trechos selecionados estão, assim, organizados conforme a maneira como apresentam indícios alusivos às categorias de representação e recursão na linguagem. Aqueles que sugerem essa alusão de forma que consideramos mais geral nos serviram de ponto de partida para a discussão; os que remetem a aspectos que nos parecem mais específicos em torno dessas categorias seguiram-se aos primeiros, guiando-nos na construção da argumentação. 
No exemplo (1), a seguir, a narradora personagem de A paixão segundo G.H. alude a um escuro não iluminável em que consistiria a coisa em si:

(1) Não sei, não sei. Pois a coisa nunca pode ser realmente tocada. O nó vital é um dedo apontando-o - e, aquilo que foi apontado, desperta como um miligrama de radium no escuro tranquilo. Então ouvem-se os grilos molhados. A luz do miligrama não altera o escuro. Pois o escuro não é iluminável, o escuro é um modo de ser: o escuro é o nó vital do escuro, e nunca se toca no nó vital de uma coisa. A coisa para mim terá que se reduzir a ser apenas aquilo que rodeia o intocável da coisa? (LISPECTOR, 1998d, p. 138).

A narradora sugere que qualquer perturbação no "halo" da coisa em si não provoca descortino, de modo que o abalo resultante resta circunscrito à atmosfera que envolve seu nó vital; não alcança o próprio nó. A forte carga poética do discurso não nos impede de aproximá-lo ao conceito kantiano de númeno e suas implicações. Para Kant (2009), a possibilidade do númeno, isto é, da coisa em si, não é passível de ser percebida por nós; fora da esfera dos fenômenos, nada há que uma extensão vazia para a nossa intuição sensível. Segundo o filósofo, embora não possamos descartar de modo geral a existência de uma intuição não sensível, sob o risco de admitirmos apenas um mundo concebido no pensamento, em razão de nossa constituição subjetiva, a intuição sensível é única para nós; conhecemos as coisas não como são, mas como parecem ser. O númeno não é, pois, para nós, um objeto inteligível, é "[...] algo de que não podemos fazer a menor representação" (KANT, 2009, p.186); ele não constitui "[...] um conhecimento determinado de uma coisa qualquer, mas somente o pensamento de alguma coisa em geral em que faço abstração de toda forma de intuição sensível" (KANT, 2009, p. 183).

Conforme Figueiredo (2005), o idealismo transcendental kantiano rompe com a tradição filosófica platônica ao negar que corresponderiam ao inteligível e ao sensível dois níveis diversos de realidade, um menos real (sensível) que o outro (inteligível). Kant teria derrubado o privilégio do inteligível deixando de atribuir-lhe a determinação de uma realidade e sustentando a incidência dessa determinação sobre os fenômenos.

De fato, para Kant (2009), o fenômeno, que “[...] nada pode ser por si só e fora de nosso modo de representação" (p. 183), é a única forma sob a qual os objetos nos são dados:

\footnotetext{
Todas as nossas representações são relacionadas a algum objeto pelo entendimento e, uma vez que os fenômenos são apenas representações, o entendimento os relaciona a alguma coisa apreendida como objeto da intuição sensível; mas essa coisa (na qualidade de objeto de uma intuição em geral), nessa relação, é tão somente o objeto transcendental. Por esse objeto devemos entender alguma coisa $=x$, da qual nada sabemos e [...] nada podemos saber; mas essa coisa pode, como correlativo da unidade da percepção, servir apenas para unificar a multiplicidade na intuição sensível, operação pela qual o entendimento liga essa multiplicidade ao conceito de um objeto. Esse objeto transcendental não deve nunca estar separado dos dados sensíveis, pois se assim fosse, nada restaria que servisse para concebêlo. Portanto, ele não é um objeto do conhecimento em si, mas somente a representação dos fenômenos no conceito de um objeto em geral, que pode ser determinado pela multiplicidade dos fenômenos (KANT, 2009, p. 182-183).
} 
Apesar da permanência de um princípio dualista na proposta kantiana, que reitera a tradição essencialista, percebemos no pensamento do filósofo a desestabilização do conceito de representação como reprodução acurada. Ao sustentar a subordinação de nosso conhecer à intuição sensível, Kant evidencia o problema da noção de objetividade e estreita o fosso entre o cognoscível e o cognoscente.

No exemplo (2), a seguir, a narradora de $A$ cidade sitiada, ao refletir sobre a atitude da protagonista do romance, parece aludir a essa realidade fenomênica:

(2) Oh, mas as coisas não eram jamais vistas: as pessoas é que viam. [...] Que diria então se pudesse passar, de ver os objetos, a dizê-los... Era o que ela, com paciência de muda, parecia desejar. Sua imperfeição vinha de querer dizer, sua dificuldade de ver era como a de pintar. O difícil é que a aparência era a realidade. (LISPECTOR, 1998a, p. 72).

A narradora atribui a angústia da personagem à impossibilidade de a coisa em si ser vista de maneira isenta, livre do olhar dos sujeitos. Em sua afirmação de que a aparência era a realidade, percebemos apreciação semelhante à de Kant, o qual postula que a definição real, isto é, a compreensão da possibilidade do objeto de uma categoria está inextricavelmente vinculada às condições da sensibilidade dos sujeitos, portanto à forma dos fenômenos.

Ao indicar como dificuldade essa identificação entre aparência e realidade e apontála como um obstáculo que se interpunha ao seu desejo de dizer o mundo, a narradora de Clarice nos chama a atenção, ainda nesse exemplo, para o aspecto que naturalmente emerge do questionamento da noção clássica de representação: o lugar da linguagem na significação. Uma vez que contestamos essa noção clássica, apoiando-nos na crença de que a realidade pré-linguagem é imprecisa, etérea, amorfa, não entendemos como imperfeição o nosso "querer dizer", como parece supor nesse trecho a narradora.

A personagem G.H., por sua vez, ao narrar sua experiência epifânica, parece partilhar de nossa crença, como observamos no exemplo (3), a seguir:

(3) Mas é que também não sei que forma dar ao que me aconteceu. E sem dar uma forma, nada me existe. E - e se a realidade é mesmo que nada existiu?! quem sabe nada me aconteceu? Só posso compreender o que me acontece mas só acontece o que eu compreendo - que sei do resto? o resto não existiu. Quem sabe nada existiu! Quem sabe me aconteceu apenas uma lenta e grande dissolução? E que minha luta contra essa desintegração está sendo esta: a de tentar agora dar-lhe uma forma? Uma forma contorna o caos, uma forma dá construção à substância amorfa - a visão de uma carne infinita é a visão dos loucos, mas se eu cortar a carne em pedaços e distribuí-los pelos dias e pelas fomes - então ela não será mais a perdição e a loucura: será de novo a vida humanizada. [...] Mas como faço agora? Devo ficar com a visão toda, mesmo que isso signifique ter uma verdade incompreensível? ou dou uma forma ao nada, e este será o meu modo de integrar em mim a minha própria desintegração? (LISPECTOR, 1998d, p. 14).

$\mathrm{Na}$ tentativa de compreender e contar a própria experiência, a narradora personagem pondera se o seu esforço não seria mais do que o de reconstituir; se não seria dando-se forma ao nada, oferecendo-se contorno ao caos, cortando-se em pedaços a "carne infinita", que se criaria o que existe. Identificamos no trecho uma referência ao aspecto constitutivo da linguagem, o qual remonta à tese humboldtiana, que endossa, conforme Franchi ([1977] 1992), a concepção de língua como processo criador pelo qual damos forma ao conteúdo impreciso e variável de nossas experiências. 
Considerando essa concepção um clichê metodológico precário, Blikstein (2003) aponta sua reformulação como um avanço epistemológico inevitável, por julgar a significação linguística tributária do referente. Para o autor, “[...] o universo e o próprio pensamento já começam a se organizar na percepção/cognição, antes, portanto da própria linguagem" (p. 45); o recorte oferecido pela linguagem não seria, assim, o recorte da realidade propriamente, mas o recorte da realidade fabricada, da realidade transformada em referente. Organizar o caos, dar forma ao nada, cortar em pedaços a "carne infinita" seria, sob esse ponto de vista, um processo desencadeado "atrás" da linguagem.

Nos exemplos (4) e (5), a seguir, a narradora autodiegética de Água viva, uma artista plástica que procura compor uma espécie de retrato narrativo da consciência do tempo e do espaço, faz alusão a uma dimensão da significação que, assim como na proposta de Blikstein, segundo nosso entendimento, estaria "atrás" da linguagem ou do que ela denomina pensamento primário:

(4) Parece-me que o mais provável é que não entendo porque o que vejo agora é difícil: estou entrando sorrateiramente em contato com uma realidade nova para mim que ainda não tem pensamentos correspondentes e muito menos ainda alguma palavra que a signifique: é uma sensação atrás do pensamento. (LISPECTOR, 1998e, p. 44).

(5) Quando se vê, o ato de ver não tem forma - o que se vê às vezes tem forma, às vezes não. $\mathrm{O}$ ato de ver é inefável. E às vezes o que é visto também é inefável. E é assim certa espécie de pensar-sentir que chamarei de "liberdade", só para lhe dar um nome. Liberdade mesmo enquanto ato de percepção - não tem forma. E como o verdadeiro pensamento se pensa a si mesmo, essa espécie de pensamento atinge seu objetivo no próprio ato de pensar. Não quero dizer com isso que é vagamente ou gratuitamente. Acontece que o pensamento primário enquanto ato de pensamento - já tem forma e é mais facilmente transmissível a si mesmo, ou melhor, à própria pessoa que o está pensando; e tem por isso - por ter forma - um alcance limitado. Enquanto o pensamento dito "liberdade" é livre como o ato de pensamento. É livre a um ponto que ao próprio pensador esse pensamento parece sem autor. (LISPECTOR, 1998e, p. 81-82).

O "pensamento liberdade", conceptualizado nesses trechos pela narradora de Clarice, aproxima-se a nosso ver do sistema perceptual-cognitivo descrito por Blikstein (2003). A discretização do mundo, a transformação da realidade nova, sem pensamentos correspondentes, nas palavras da narradora, em realidade fabricada, nas palavras de Blikstein, dar-se-ia a partir dessa dimensão interposta entre a linguagem e massa amorfa do real.

Ao afirmar em (5) que "o que se vê às vezes tem forma, às vezes não", a narradora nos permite ainda enxergar no "pensamento liberdade" um elemento crucial na dimensão da percepção-cognição concebida no esquema proposto por Blikstein. Na discussão empreendida pelo autor a respeito do filme de Werner Herzog, O Enigma de Kaspar Hauser, de 1974, ele argumenta que sem a práxis social, não há significação:

\footnotetext{
Kaspar Hauser descodifica de modo sempre aberrante a significação do mundo. A permanência do déficit cognitivo de Kaspar Hauser seria um índice de que os elementos que modelam a percepção do mundo e as configurações conceituais podem ser capturados não só na linguagem mas sobretudo na dimensão da práxis (p. 55).
} 
Conforme explica Blikstein, a práxis modela a percepção-cognição a partir de mecanismos que consistem em traços de diferenciação e identificação que o "[...] homem cognoscente desenvolve [...] para mover-se no tempo e no espaço de sua comunidade" (BLIKSTEIN, 2003, p. 60). O autor esclarece que, a partir de tais traços, somos capazes de "[...] discriminar, reconhecer e selecionar [os elementos] do universo amorfo e contínuo do real" (BLIKSTEIN, 2003, p. 60). Acrescenta que, ao serem impregnados de valores meliorativos ou pejorativos, esses traços transformam-se em traços ideológicos, os quais desencadeiam corredores semânticos ou isotopias, que, por sua vez, orientam a percepção-cognição, criando modelos ou padrões perceptivos, os "óculos sociais".

Assim, ao mesmo tempo que nos permite a discretização de um universo amorfo e contínuo, a dimensão da práxis a que estaria necessariamente sujeita nossa percepçãocognição reitera padrões perceptivos, que relativizam a ausência de forma desse universo. De acordo com nossa compreensão, é consoante com essa ideia o que declara a narradora de Clarice no exemplo (5): o que pensa o "pensamento liberdade", que a narradora assim denominou, "só para lhe dar um nome", "às vezes tem forma, às vezes não". Ousamos afirmar, com base na explicação de Blikstein, que, embora o "pensamento liberdade" não seja determinado como o "pensamento primário", é justamente em razão dos "óculos sociais" que, como alerta a narradora, tal pensamento não ocorre "vagamente ou gratuitamente" e, por outro lado, "ao próprio pensador esse pensamento parece sem autor".

Ocorre que, nas palavras de Blikstein, “[...] embora a significação dos códigos verbais seja tributária, em primeira instância, da semiose não verbal, é praticamente só por meio desses códigos verbais que podemos nos conscientizar da significação escondida na dimensão da práxis" (BLIKSTEIN, 2003, p. 80), isto é, a semiose não verbal, da qual temos apenas frágil consciência, só pode ser explicada pela língua, que por sua vez a reitera e a subverte, (re)organizando "[...] toda uma estrutura de movimentos, espaços, distâncias, gestos, objetos, construída pela estereotipia da nossa percepção" (BLIKSTEIN, 2003, p. 74).

Essa possibilidade subversiva na interação língua-práxis é, para o autor, o que se manifesta no conflito de Kaspar Hauser: ao desarranjar os corredores isotópicos e os estereótipos, as condições de aquisição de linguagem a que foi submetido o personagem - um momento tardio da vida e um ambiente socialmente restrito - denunciam a fabricação da realidade. No exemplo (6), a seguir, percebemos na argumentação da narradora G.H., de Clarice, certa alusão a essa "práxis libertadora" de que fala Blikstein:

(6) Mas era como uma pessoa que, tendo nascido cega e não tendo ninguém a seu lado que tivesse tido visão, essa pessoa não pudesse sequer formular uma pergunta sobre a visão: ela não saberia que existia ver. Mas, como na verdade existia a visão, mesmo que essa pessoa em si mesma não a soubesse e nem tivesse ouvido falar, essa pessoa estaria parada, inquieta, atenta, sem saber perguntar sobre o que não sabia que existe - ela sentiria falta do que deveria ser seu. (LISPECTOR, 1998d, p.135).

A "práxis libertadora", fruto da subversão de modelos perceptocognitivos contingencialmente determinados, "[...] acaba por patentear como a realidade tão bem ordenada e natural é apenas um produto da práxis da comunidade" (BLIKSTEIN, 2003, p. 86). G.H., ao afirmar hipoteticamente que a pessoa cega, tendo assim nascido e vivido entre outras igualmente privadas de visão, não saberia de que sentia falta ainda que 
sentisse a falta, parece justamente argumentar que o real existe para nós conforme a percepção moldada pela práxis. E ao insistir que, mesmo ignorando que "ver" existia, tal pessoa restaria inquieta, com a angústia de uma pergunta que não saberia formular, a narradora problematiza a aceitação do real fabricado para a nossa percepção.

Entendemos essa problematização do real fabricado como a compreensão de que é aparente a naturalidade das estruturas ordenadas que confortavelmente admitimos, como a quebra da "ilusão referencial" nos termos de Blikstein. A nosso ver, essa quebra é o reconhecimento, como possibilidade, de uma realidade outra; tratar-se-ia de um equívoco percebê-la como sinal acusador de uma realidade una, última.

Com base na proposta teórica do biólogo Humberto Maturana, afirmamos que pensar a realidade em termos ontológicos não pode ser distinto, para nós, de pensá-la em termos epistemológicos, pois "[...] o fenômeno do conhecer é um fenômeno do vivo" (MATURANA, 2001, p. 40). Nesse sentido, o mundo não é; "[...] o mundo se explica [...] com o suceder do viver, com a práxis e o viver na linguagem" (MATURANA, 2001, p. 58). Segundo o autor, a assunção de que não há referência a uma realidade independente não é caótica ou temerária, porque não se trata de concebê-la como uma fantasia discursiva, mas de percebê-la como uma proposição explicativa, uma versão configurada conforme domínios de coerências operacionais.

O que fazemos na linguagem é, para Maturana, consensualmente coordenar ações e coordenações consensuais de ações; a história dessa recursão, isto é, o que fazemos emergir no fluxo dessas coordenações de coordenações é o que existe. De acordo com o autor, fora da linguagem, nada existe que diga respeito a nós, sistemas vivos linguajantes que somos: "Nós já nos encontramos na linguagem, fazendo distinções na linguagem, quando começamos a refletir na linguagem sobre o que fazemos, e como fazemos o que fazemos" (MATURANA, 2001, p. 125).

Como a linguagem é "[...] o fluir na recursão das coordenações consensuais de comportamento" (p. 98), é nela que, conforme salienta Maturana, tomam forma as entidades do mundo. Estas seriam comparadas a nós, a "[...] entroncamentos no espaço de coordenações de ação" (p. 99). Apenas se pensarmos a realidade em termos essenciais, em termos de um mundo objetivo e independente, é que a linguagem aparece como limitação, como mediador deficiente. No exemplo (7), a seguir, a narradora de Clarice parece admitir que pode somente permanecer alheia, vaga, indistinta, essa "[...] base absolutamente invisível, a partir da qual surge o que surge na linguagem" (MATURANA, 2001, p. 98):

\footnotetext{
(7) Minha voz é o modo como vou buscar a realidade; a realidade, antes de minha linguagem, existe como um pensamento que não se pensa, mas por fatalidade fui e sou impelida a precisar saber o que o pensamento pensa. A realidade antecede a voz que a procura, mas como a terra antecede a árvore, mas como o mundo antecede o homem, mas como o mar antecede a visão do mar, a vida antecede o amor, a matéria do corpo antecede o corpo, e por sua vez a linguagem um dia terá antecedido a posse do silêncio. Eu tenho à medida que designo - e este é o esplendor de se ter uma linguagem. Mas eu tenho muito mais à medida que não consigo designar. A realidade é a matéria-prima, a linguagem é o modo como vou buscá-la - e como não acho. Mas é do buscar e não achar que nasce o que eu não conhecia, e que instantaneamente reconheço. A linguagem é o meu esforço humano. Por destino tenho que ir buscar e por destino volto com as mãos vazias. Mas - volto com o indizível. O indizível só me poderá ser dado através do fracasso de minha linguagem. Só quando falha a construção, é que obtenho o que ela não conseguiu. (LISPECTOR, 1998d, p. 175-176).
} 
Ao indicar a linguagem, a própria voz, como modo de buscar a realidade sem encontrá-la, e apontar essa realidade como um a priori que se apresenta apenas como matéria-prima, bruta, não como dado recuperável, a narradora parece endossar o ponto de vista de Maturana (2001, p. 153): "Os objetos, a consciência, a autorreflexão, o self, a natureza, a realidade, e assim por diante, tudo o que nós, seres humanos, fazemos e somos acontece na linguagem como distinções ou como explicações na linguagem do nosso estar na linguagem".

Percebemos ainda na reflexão da narradora, quando afirma voltar da busca de mãos vazias e não obstante com o indizível, apenas obtido pelo "fracasso" da linguagem, certa congruência com a ideia central subjacente à biologia do conhecer, a de "[...] nossa participação constitutiva no produzir o mundo que vivemos" (MATURANA, 2001, p. 155). Se não há realidade previamente distinta a ser desvelada, as mãos da narradora só poderiam voltar vazias. E se por essa razão "fracassa" a linguagem, o "fracasso" é produtivo porque obtemos o indizível no fluir em recursão nas coordenações consensuais de ação, pois “[...] tudo o que distinguimos, nós distinguimos na linguagem; tudo o que experienciamos, nós experienciamos ao distinguirmos na linguagem nossa experiência" (p. 155).

\section{CONSIDERAÇÕES FINAIS}

Neste artigo tivemos como objetivo discutir as noções de representação e recursão a partir do discurso metalinguístico presente em romances de Clarice Lispector. Com base nas contribuições teóricas de autores que, em diferentes áreas do conhecimento, fomentaram o debate epistemológico acerca dessas noções, como o filósofo Kant, o linguista Izidoro Blikstein e o biólogo Humberto Maturana, analisamos trechos das obras A cidade sitiada, Água viva e A paixão segundo G.H.

Tendo em vista nosso propósito, discutimos posicionamentos teóricos que consideramos de notável relevância para o exame do recorrente e inquietante questionamento a respeito da relação entre linguagem e realidade, os quais julgamos estarem inseridos numa trajetória delineada entre a desestabilização da ideia de representação como reprodução acurada do real e a construção da noção de recursão como uma plausível alternativa antirrepresentacionista.

Explorando as cogitações linguístico-filosóficas que compõem o discurso construído nas obras de Clarice mencionadas, mostramos certa proximidade entre esse discurso e a crítica kantiana, que identificamos como os passos inaugurais em direção à problematização do conceito tradicional de representação. Além disso, apontamos no discurso metalinguístico da autora alusão à existência de uma semiose anterior à língua como componente da experiência perceptiva e à sujeição da percepção-cognição à práxis social, premissas do esquema bliksteiniano elaborado para explicar como fabricamos a realidade. Indicamos, ainda, insinuar-se em tal discurso a ideia de que não capturamos o real, mas o produzimos ao explicar nosso estar no mundo, que é também nosso estar na linguagem, com o meio e com os outros, portanto um fluir em recursão nas coordenações consensuais de ação. 
Reiteramos que a manifestação dessas alusões e remissões no discurso analisado não obedece a um tipo de trajetória evolutiva, como um conflito que se estabelece nas primeiras obras e se dissolve nas derradeiras. Tão complexos quanto os anseios e os juízos dos personagens de Clarice, os argumentos que constituem o discurso autorreflexivo da autora são contrapontísticos, não redutíveis.

Consideramos oportuna a discussão aqui empreendida em virtude da evidente relevância que carrega a reflexão sobre a relação linguagem-mundo, que há muito, desde a Antiguidade Clássica pelo menos, tem sido tema de debate. As bases filosóficas que amparam essa reflexão auxiliam, a nosso ver, em larga medida, a urgente compreensão do protagonismo da linguagem na constituição de nossas práticas sociais. A urgência a que nos referimos se dá em face da recorrência, seja no âmbito mais restrito de nossas interações cotidianas, seja na dimensão mais global de nossas ações e decisões políticas, de problemas advindos de visões que ignoram ou negligenciam a opacidade da linguagem. Além de alimentar essa reflexão, ao oferecer leituras possíveis para os romances de Clarice abordados, este trabalho pode favorecer, em certo grau, o ensino e a compreensão da obra da autora.

\section{REFERÊNCIAS}

BARROS, A. K.; COSTA, M. H. A. Linguagem, cognição e referência em A maçã no escuro. Acta Scientiarum. Language and Culture, v. 37, p. 381-391, 2015.

BLIKSTEIN, I. Kaspar Hauser ou a fabricação da realidade. 9. ed. São Paulo: Cultrix, 2003.

COSTA, M. H. A. Acessibilidade de referentes: um convite à reflexão. 2007. 214f. Tese (Doutorado em Linguística) - Programa de Pós-graduação em Linguística, Universidade Federal do Ceará, Fortaleza, 2007.

FIGUEIREDO, V. de. Kant e a crítica da razão pura. Rio de Janeiro: Zahar, 2005.

FRANCHI, C. Linguagem - atividade constitutiva. Cadernos de Estudos Linguísticos, Campinas, n. 22, p. 9-39, 1992.

GHIRALDELLI P. Virada linguística - um verbete. Disponível em:

〈https://ghiraldelli.files.wordpress.com/2008/07/virada.pdf>. Acesso em: 28 mar. 2017.

KANT, I. Crítica da razão pura. Tradução de Lucimar Coghi e Fulvio lubisco. São Paulo: Martin Claret, 2009.

LISPECTOR, C. A cidade sitiada. Rio de Janeiro: Rocco, 1998a.

A hora da estrela. Rio de Janeiro: Rocco, 1998 b.

A maçã no escuro. Rio de Janeiro: Rocco, 1998c.

A paixão segundo G.H. Rio de Janeiro: Rocco, 1998d.

Água viva. Rio de Janeiro: Rocco, 1998e.

Perto do coração selvagem. Rio de Janeiro: Rocco, $1998 \mathrm{f}$.

MAGRO, C. O que a biologia do linguista pode dizer para o linguista. Estudos Linguísticos, São Paulo, v. 29, p. 270-275, 2000.

C. Valor de Fato. In: VAITSMAN, J; GIRARDI, S. (Org.) A ciência e seus impasses: debates e tendências. Rio de Janeiro: FIOCRUZ, 1999. p. 93-108.

Representação, Virtus Dormitiva e linguagem. In: OLIVEIRA, P.; BENN-IBLER, V.;

MENDES, E. (Org.) Revisitações: Edição Comemorativa dos 30 anos da Faculdade de Letras. Belo Horizonte: Editora FALE/UFMG, 1999 b.

C. O que é uma teoria da linguagem. In: PINTO, P. M. et al. (Org.) Filosofia Analítica, Pragmatismo e Ciência. Belo Horizonte: Editora UFMG, 1998. p. 177-189. 
MATURANA, H. Cognição, ciência e vida cotidiana. Tradução de Cristina Magro e Victor Paredes. Belo Horizonte: Ed. UFMG, 2001.

A ontologia da realidade. Organização de Cristina Magro, Miriam Graciano e Nelson Vaz. Belo Horizonte: Editora UFMG, 1997.

MATURANA, H.; VARELA, F. A árvore do conhecimento: as bases biológicas do entendimento humano. Campinas: Psy II, 1995.

NUNES, B. O drama da linguagem: uma leitura de Clarice Lispector. 2. ed. São Paulo: Ática, 1995.

REGO, P. C. Kant: A revolução copernicana na filosofia. In: FIGUEIREDO, V. de (Org.) Seis filósofos em sala de aula. São Paulo: Berlendis e Vertecchia, 2006. p. 149-191.

TREVISAN, D. K. O problema da linguagem no discurso filosófico kantiano como questão políticojurídica. Cadernos de Filosofia Alemã: Crítica e Modernidade. São Paulo, n. 20, p. 81-100, 2012.

WITTGENSTEIN, L. Tractatus logico-philosophicus. São Paulo: Companhia Editora Nacional, 1968.

Recebido em: 21/07/17. Aprovado em: 10/04/18.

Title: Language, representation and recursion in Clarice Lispector's metalinguistic discourse

\begin{abstract}
Authors: Alana Kercia Barros Demétrio; Maria Helenice Araújo Costa
Abstract: This article discusses notions about the human attribute of constructing meaning. It aimed to discuss from the metalanguage in Clarice Lispector's novels the notions of representation and recursion. It adopts, as theoretical framework, considerations by authors from different areas of knowledge, who fostered, in their studies, the epistemological debate about these notions, such as the philosopher Kant, the linguist Izidoro Blikstein and the biologist Humberto Maturana. In light of these theoretical contributions, it analyzes passages from the novels A cidade sitiada, Água viva and A paixão segundo G.H., in which it identifies the presence of reflections about the unachievable challenge of representation. In these passages it observes the allusion to a nonverbal semiosis hidden in the dimension of a praxis that is prior and yet tributary to the language; and notices the idea that subjects construct senses in the flow of recursive coordination in the praxis of living.
\end{abstract}

Keywords: Language. Representation. Recursion. Praxis of living. Clarice Lispector.

Título: Lenguaje, representación y recursión en el discurso metalingüístico de Clarice Lispector

Autoras: Alana Kercia Barros Demétrio; Maria Helenice Araújo Costa

Resumen: Este artículo problematiza nociones sobre el atributo humano de construir sentidos. Objetiva discutir nociones de representación y recursión desde el metalenguaje presente en romances de Clarice Lispector. Adopta, como referencial teórico, consideraciones tejidas por autores de diferentes áreas de conocimiento, que en sus estudios, han fomentado el debate epistemológico acerca de estas nociones, como el filósofo Kant, el lingüista Izidoro Blikstein y el biólogo Humberto Maturana. Bajo la luz de esas contribuciones teóricas, analiza partes de los romances A cidade sitiada, Água viva e A paixão segundo G. H., en que identifica la presencia de reflexiones sobre el desafio insuperable de la representación. En las partes analizadas, observa la alusión a una semiosis no verbal oculta en la dimensión de una praxis anterior a la lengua, pero al mismo tiempo de ella tributaria; y percibe la idea de que los sujetos construyen los sentidos en el fluir de recursiones de la praxis del vivir.

Palabras clave: Lenguaje. Representación. Recursión. Praxis del vivir. Clarice Lispector.

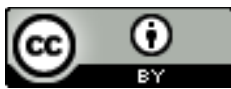

Este texto está licenciado com uma Licença Creative Commons Atribuição 4.0 Internacional.

DEMÉTRIO, Alana Kercia Barros; COSTA, Maria Helenice Araújo. Linguagem, representação e recursão no discurso metalinguístico de Clarice Lispector. Linguagem em (Dis)curso - LemD, Tubarão, SC, v. 18, n. 2, p. 323-339, maio/ago. 2018. 